\title{
Proposta de Melhoria do Processo de Contratação de Serviços de TI e da Gestão dos Contratos na Administração Pública Federal
}

\author{
Proposal for Improving the Hiring Process and IT Service Management Contract \\ at Federal Public Administration
}

José Gonçalo dos Santos ${ }^{1}$

\begin{abstract}
Resumo: Este trabalho se baseou numa análise exploratória com objetivo de analisar e mapear os processos de contratação de serviços de TI na Administração Pública Federal, tomando como base o Ministério da Ciência, Tecnologia e Inovação - MCTI, com uso das técnicas de modelagem de processos baseados na notação BPMN. Inicialmente, foi feita a modelagem dos processos atuais (AS-IS), e em seguida foi feita uma análise dos resultados. O trabalho foi feito com base na análise da IN 02/2010, Lei 10520/2002 e Lei 8666/1993. Com base nesta análise, os processos atuais foram mapeados. Os principais objetivos foram: identificar os processos de contratação de serviços de TI que estão relacionados com os projetos do órgão; analisar os processos de contratação de serviços de TI; modelar os processos de contratação de serviços de TI com notação BPMN; identificar os processos críticos de contratação de serviços de TI e propor melhorias.
\end{abstract}

PALAVRAS-CHAVE: BPM, BPMN, Licitação, Contrato Administrativo.

Abstract: This work was based on an exploratory analysis in order to analyze and map the processes of hiring IT services at Federal Public Administration, based on the Ministry of Science, Technology and Innovation - MCTI, using the techniques of process modeling based on the BPMN notation. Initially, it was made the modeling of current processes (AS-IS), and then an analysis of the results. The work was done based on the analysis of IN 02/2010, Law 10520/2002 and Law 8666/1993. Based on this analysis the current processes were mapped. The main objectives were to: identify the processes of hiring IT services that are related to the projects of the agency; analyze the processes of hiring IT services; to model the processes of hiring IT services with BPMN notation; identify the critical processes of hiring IT services and propose improvements.

KEY-WORDS: BPM, BPMN, Bidding, Administrative Contract.

\section{Introdução}

A terceirização de serviços de Tecnologia da Informação (TI) na Administração Pública Federal (APF) vem sendo feita há muito tempo, mas não de maneira adequada. A partir do decreto 200/1967 (BRASIL, 1967), onde diz que a APF deve se concentrar na tarefa de planejamento, coordenação, descentralização, delegação de competência e controle, e que os serviços como transporte, informática e coperagem devem ser feitos por terceiros, a TI vem sendo

\footnotetext{
${ }^{1}$ Instituto Federal de Educação, Ciência e Tecnologia de Brasília (IFB) - Campus Gama.
} 
terceirizada sem critérios.

Diante de tais fatos, muitos decretos, normas e acórdãos foram editados, cujos objetivos são implantar a governança de TI na APF e normatizar a contratação de serviços relacionados à TI. Nesse sentido, Cruz (2008) fez um quadro referencial normativo para contratação de serviços de Tecnologia da informação. A sua motivação se residiu no fato de que esse decreto facilitou a terceirização desses serviços, e que isso poderia trazer vulnerabilidades e riscos, sendo exemplos deste: de segurança da informação, de dependência de terceiros e de ordem legal.

Conforme acórdão TCU - 786/2006, em Brasil (2006 apud Cruz, 2008), o risco de dependência de terceiros já se materializou em muitas organizações públicas que terceirizaram completamente suas áreas de TI, pois perderam, inclusive, sua capacidade de gerenciar adequadamente os próprios contratos de serviços. 0 que evidencia esse fato é identificação de irregularidades, pelo Tribunal de Contas da União (TCU), nas contratações de serviços de TI da esfera federal, recorrentemente relacionadas com a falta de capacidade de gerenciar tais contratos, o que prejudica a governança de TI, a governança corporativa e a governança estatal (CRUZ, 2008, p. 18-19). Cruz (2008, p. 19) ainda acrescenta que "a gestão de contratações de serviços de TI no setor público deve pautar-se pelo conhecimento objetivo dos requisitos legais e regulatórios aplicáveis aos processos de TI e pela garantia de que tais processos estejam em conformidade com a legislação".

Nesse sentido, a Secretaria de Logística e Tecnologia da Informação (SLTI) pertencente ao Ministério do Planejamento Orçamento e Gestão (MPOG), que é órgão central do Sistema de Administração dos Recursos de Informação e Informática - SISP, criou a Instrução Normativa MP - IN 04/2008 (BRASIL, 2008) para normatizar a contratação e gestão de contratos de serviços de TI. Em 2010 uma nova versão, revisada, da IN 04 foi publicada.

O grande problema encontrado pela APF, o que não é diferente no Ministério da Ciência, Tecnologia e Inovação (MCTI), para aplicar essa instrução é a falta de servidores com capacidade de interpretá-la de forma adequada. Nesse sentido, torna-se necessário o mapeamento desse processo de forma a prover um roteiro para facilitar futuras contratações de serviços de TI, bem como a gestão destes. Este roteiro deve ter uma interface simples e fácil compreensão. Dessa forma, a notação BPMN, é a mais indicada, pois segundo Filho e Assad (2007, 17-18), ela é uma especificação para modelagem visual de processos, que estabelece uma interface simples e de fácil compreensão, acessível tanto para analistas de sistemas como para profissionais de O\&M, gestores de processos de negócios e tradicionais usuários de TI que encontram nele uma linguagem visual comum.

Assim, a principal motivação para realização deste trabalho foi a dificuldade encontrada no momento da elaboração dos termos de referência para contratação de serviços de TI. Dessa forma, o objetivo deste trabalho é fazer uma análise do processo geral, macroprocesso, e subdividi-lo em subprocessos de forma a diminuir a sua complexidade para, em seguida, fazer o mapeamento destes para melhor entendê-los para que se possa detectar as falhas e propor melhorias. 
Para o desenvolvimento deste trabalho, visando o objetivo acima, foi usada a metodologia de análise exploratória, cuja hipótese de pesquisa foi: "este estudo pode dar subsídio para uma proposta de melhoria?"

Este artigo está estruturado da seguinte forma: nesta Seção são apresentados, em linhas gerais, o problema e justificativa, os objetivos e a estrutura do trabalho; na Seção 2 é apresentado o embasamento teórico, onde são tratados os assuntos relacionados a modelagem de processos de negócio (BPM) e notação de modelagem de processos de negócio (BPMN); na Seção 3 é apresentada a modelagem AS-IS; na Seção 4 é analisado o modelo AS-IS; na Seção 5 são apresentadas as discussões dos resultados e é apresentada a proposta de melhoria (TO-BE). Na Seção 6 é apresentada a conclusão.

\section{Revisão de Literatura}

Nesta Seção é apresentado o embasamento teórico a respeito da modelagem de processos, cujo intuito é dar sustentação ao trabalho desenvolvido.

\subsection{Modelagem de Processos de Negócios}

Antes da definição da modelagem de processo de negócios propriamente dito, se faz necessário definir alguns termos importantes para o seu entendimento, a saber: modelagem de processo e processo de negócio, os quais são apresentados a seguir.

Modelagem de Processos é o termo utilizado tanto para mapeamento como para redesenho de processo. Ambos os termos são definidos a seguir (MPOG, 2007).

Mapeamento é o levantamento e diagramação do processo como ele é executado (atual) (As Is). É entendido como a identificação dos fluxos de trabalho com início, meio e fim bem determinados, com insumos e produtos ou serviços claramente definidos e com atividades que seguem uma seqüência lógica, permitindo uma visão integrada e encadeada do trabalho.

Redesenho é a otimização (melhoria) do processo (proposta). É entendido como as melhorias realizadas por meio da racionalização do fluxo de trabalho. Gera uma base referencial que permite, entre outras aplicações, criar condições para a construção da estrutura organizacional, a definição e avaliação de indicadores de resultados de atendimento em nível interno e/ou institucional, a formulação de planos de sistemas de informações e a aplicação do Ciclo PDCA (Plan Do Check Action - Planejar Fazer Verificar Corrigir, em português).

O termo processo de negócio, embora abstrato, pode ser exemplificado de diversas formas. Uma definição bastante simplista e prática para entendê-lo é por meio de analogia com processos tangíveis como os realizados nas linhas de produção em que se pode verificar um trabalho executado por meio de diferentes atividades sequenciais, que corroboram para a composição do produto final. Muitas das técnicas e conceitos aplicados à gestão por processos foram concebidas em áreas fora da administração, sobretudo na engenharia de produção, mais 
especificamente nas práticas do gerenciamento operacional (ARMISTEAD et al., 1995 apud SORDI et al, 2009).

O processo de negócio é composto por diversas etapas de produção ou atividades a serem executadas. Esta ideia de dividir o trabalho em atividades sequenciais surgiu em meados do século XVIII, no início da Revolução Industrial, quando a mecanização exigiu a divisão do trabalho (SORDI, 2009).

Tendo entendido os conceitos apresentados anteriormente é possível entender Modelagem de processos de negócio que, de acordo com Vieira (2006), consiste em conduzir a melhoria dos processos de negócio da organização, otimizando a utilização de seus recursos e permitindo criar condições para acompanhar a sua performance e o cumprimento de suas metas.

Independente do porte das organizações, a modelagem traz alguns benefícios, como por exemplo: redução de custos, redução do tempo de execução, melhoria da qualidade, aumento da produtividade, maior foco na satisfação dos clientes internos e externos, agilidade no gerenciamento de mudanças e maior compreensão da organização.

Para Vieira (2006) um projeto de modelagem de processos deve seguir as etapas: análise preliminar - consiste na visão dos processos e priorização; elaboração de soluções e melhoria dos processos - consiste na análise e elaboração de medidas de melhorias e também na preparação para implantação; e realização de benefícios de melhoria - consiste na implantação.

A modelagem de processos de negócio tem como objetivo criar modelos de processos de negócios que, segundo Dávolos (2010, p. 20), são representações de uma organização real que servem como referência comum para todos os seus componentes, sejam recursos humanos, sistemas ou outros recursos e formam uma infraestrutura de comunicação.

Entender os processos de negócio, responsabilidades e papéis de cada área não é algo fácil. As falhas são de diversos tipos: ora pela ausência de uma atividade ou um processo de trabalho, ora por existirem atividades duplicadas.

Além disso, é muito comum, que os funcionários não tenham entendimento das atividades, dos seus objetivos, e o porquê de executarem. É importante frisar, que o entendimento comum entre todos da organização acerca do que devem fazer é primordial para a empresa nos dias atuais.

\subsection{BPM}

BPM (Business Process Management - Gestão de Processos de Negócios, em português) é o enfoque sistêmico de projetar e melhorar continuamente os processos organizacionais, por pessoas com potenciais e com capacidade de trabalhar em equipe, combinando capacidades tecnológicas emergentes e sob uma postura filosófica para a qualidade com objetivo de entregar valor ao cliente (LAURINDO, 2008, p. 27). Envolve a descoberta, projeto e entrega de processos de negócio. Além disso, BPM inclui o controle executivo, administrativo e supervisório de tais processos (BALDAM, 2007, p. 19). 
Os objetivos da gestão de processos segundo Laurindo (2008, p. 27) são:

- aumentar o valor do produto ou serviço na percepção do cliente;

- aumentar a competitividade, deslocando a concorrência via formas e condições inovadoras de negócios;

- atuar segundo estratégias competitivas consideradas mais relevantes, a saber: custos, qualidade, confiabilidade de entregas, velocidade de fluxo, flexibilidade ou outras que agregem valor ao cliente;

- aumentar sensivelmente a produtividade, com eficiência e eficácia;

- simplificar os processos, condensando ou eliminando atividades que não acrescem valor ao cliente.

Segundo Santos (2007), os processos, quando otimizados e mantidos, asseguram a competitividade e sobrevivência da organização no mercado, possibilitando maior agilidade, redução do time-to-market, de custos e desperdícios e aumento da rentabilidade.

Para o autor, a gestão por processos tem por objetivo maximizar os resultados dos processos, aumentar a satisfação dos clientes, otimizar os recursos e reduzir custos.

\subsubsection{Visão por Processo}

De acordo com Santos (2007), em um mercado globalizado e altamente competitivo as mudanças são constantes, e estar preparado para responder a essas mudanças é questão de sobrevivência e não um diferencial. Nesse sentido, os processos ajudam as empresas a ter flexibilidade e a melhorar a qualidade dos seus produtos e serviços necessária para atuar em um cenário de competição.

Vieira (2006) complementa esse conceito defendendo que a visão por processos de negócio tem como objetivo obter a estruturação dos processos de negócio da organização de acordo com a visão de desenvolvimento de seus produtos e serviços.

Com base nessa visão, é elaborada uma análise da situação frente à arquitetura do negócio, identificando suas disfunções.

Alguns dos benefícios são: obter uma maior compreensão da organização, eliminar processos e atividades redundantes e que não agregam valor, oferecer suporte para a análise de aderência de pacotes de sistemas às necessidades da organização e servir como base para: análise de partes ou aspectos da organização, simulação do funcionamento da organização; tomada de decisão sobre operações e organização da empresa; padronização e otimização da documentação; suporte à certificação ISO e utilização como ferramenta da gestão administrativa.

\subsubsection{O que é processo?}


Para Dávolos (2010, p. 62-63), o termo "processo" pode causar confusão, porque é usado com diferentes acepções. Para alguns, processo é uma tarefa, como, por exemplo, uma secretária datilografando uma carta ou um auxiliar de escritório envelopando correspondência para colocar no correio. Já para outros, este pode ser o conjunto de atividades executadas por determinado agente, como pelo gerente de um hotel, ou ainda, pode ser o conjunto de etapas da elaboração de um relatório anual da empresa ou da fabricação de um automóvel.

Para o autor, "processo também pode ser um conjunto de recursos e atividades inter-relacionadas que transformam insumos em produtos". Ele complementa dizendo que "processo é um conjunto de atividades, que por sua vez se desdobram em tarefas e estas em procedimentos". Já para Santos (2007), processo é um conjunto de atividades organizadas que consomem recursos e geram resultados. Esses resultados devem estar diretamente ligados aos objetivos e missão da empresa.

Pelas definições acima, pode se concluir que processo é uma sequência interdependente de passos a serem executados para se atingir determinado objetivo.

Com objetivo de melhorar o entendimento em relação ao assunto, Dávolos (2010, p. 68-69), apresenta uma hierarquia de processo, como pode ser visto na Figura 2.1 e descrita a seguir.

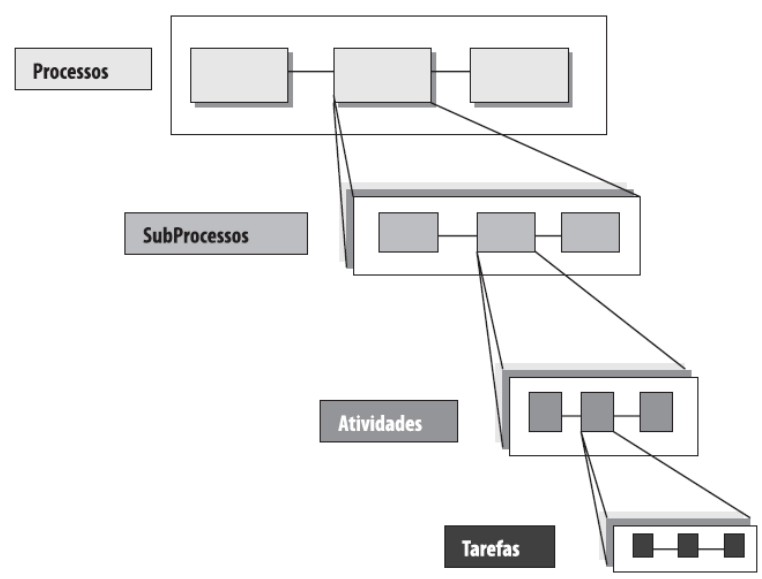

Figura 2.1: Hierarquia de Processos. Fonte: Dávolos (2010, p. 68-69).

Macroprocesso: este componente, apesar de não aparecer na figura, pode ser definido como um processo que geralmente envolve mais que uma função na estrutura organizacional, e a sua operação tem um impacto significativo no modo como a organização funciona.

Processo: é um conjunto de atividades sequenciais (conectadas), relacionadas e lógicas que tomam um insumo (input) com um fornecedor, acrescentam valor a este e produzem uma saída (output) para um consumidor. 
Subprocesso: é a parte que, inter-relacionada de forma lógica com outro subprocesso, realiza um objetivo específico em apoio ao macroprocesso e contribui para a missão deste.

Atividades: são procedimentos que ocorrem dentro do processo ou subprocesso. São geralmente desempenhadas por uma unidade (pessoa ou departamento) para produzir um resultado particular. Elas constituem a maior parte dos fluxogramas.

Tarefa: é uma parte específica do trabalho, ou melhor, o menor microenfoque do processo, podendo ser um único elemento e/ou um subconjunto de uma atividade. Geralmente, está relacionada como um item que desempenha uma incumbência específica.

\subsubsection{Regras de Negócios}

Conforme pode ser deduzido das definições da Seção anterior, um processo é constituído de um conjunto de atividades inter-relacionadas, que possui papéis, e responsáveis por transformar entradas em saídas, de acordo com as regras de negócio da organização.

Regras de negócio descrevem as operações, definições e restrições de uma organização para alcançar seus objetivos. Elas são usadas para ajudar uma organização a alcançar seus objetivos, a comunicação entre a organização e terceiros, demonstrar as obrigações legais, operar mais eficientemente, automatizar operações, entre outros (ARAUJO, 2010).

\subsubsection{Notação BPMN}

A organização BPMI (Business Process Management Initiative) foi criada no ano 2000 com o objetivo de criar padrões e uma arquitetura comum para o gerenciamento de processos de negócio, e logo veio a se juntar a esta a OMG (Object Management Group). Também a BPMI iniciou seus trabalhos com 35 empresas para criar a notação BPMN e dentre estas se encontravam a Intalio Inc., IBM, SAP, BEA, Fujitsu, WebMethods e IDS Scheer (BITENCOURT, 2007).

A primeira versão da notação BPMN foi escrita por Stephen White da IBM em 2004 e rapidamente se estabeleceu como notação padrão para Modelar Processos de Negócio. A última versão (BPMN 2.0) foi lançada no início de 2011 (OMG, 2011).

É importante enfatizar que a BPMN possui uma sólida fundamentação matemática e foi construída sobre os conceitos do Pi-Calculus, uma derivação do cálculo de processos para a representação de processos dinâmicos e móveis (AMARAL e BRITO, 2009 apud DÁVOLOS, 2010, p. 125).

Para Bitencourt (2007), a Business Process Modeling Notation (BPMN) está se consolidando como o mais importante padrão de notação gráfica aberta para desenhar e modelar processos de negócios. Com ela é possível, modelar os processos de negócio, capturando e documentando modelos atuais ( $A S-I S)$ em diagramas de fácil entendimento; projetar e descrever modelos ideais ( $T O-B E)$; estender detalhes técnicos; monitorar e mensurar o negócio com indicadores de 
desempenho baseados nas atividades dos fluxos de processos automatizados.

BPMN é, de fato, um padrão, utilizado por importantes empresas e possui grande variedade de ferramentas. O objetivo da representação gráfica é ser de entendimento rápido por todos os usuários de negócio, permitindo que analistas de negócio e TI se comuniquem de forma rápida e concisa.

Santos (2007) descreve que o BPMN fornece uma notação para expressar os processos de negócios em um único diagrama (Business Process Diagram BPD).

Para ele, o BPMN fornece uma notação que é compreendida por todos os usuários, analistas e técnicos do negócio. Garante que linguagens projetadas para a execução de processos de negócio, tais como o BPEL4WS e o BPML sejam visualmente expressos com uma notação comum.

O BPMI desenvolveu três padrões para facilitar BPM, conforme apresenta Santos (2007): BPMN: (Business Process Modeling Notation): Notação padrão para modelar processos de negócios; BPML: (Business Process Modeling Language): Linguagem padrão de desenvolvimento; e BPQL: (Business Process Query Language): Interface padrão de manutenção para distribuição e execução de processos e-business.

A notação BPMN utiliza elementos específicos para representar papéis, atividades, entradas e saídas dos processos. Santos (2007) define tais elementos da seguinte forma:

- Eventos: É algo que acontece durante um processo do negócio. Estes eventos afetam o fluxo do processo e têm geralmente uma causa (trigger) ou um impacto (result). Há três tipos de eventos: start ou início, intermediate ou intermediário e end ou final. Existe ainda o evento mensagem que indica a troca de mensagens entre duas atividades.

- Atividade ou tarefa: É um termo genérico para um trabalho executado. Os tipos de atividades são: tarefas e subprocessos. O subprocesso é distinguido por uma pequena cruz no centro inferior da figura e corresponde a um agrupamento das atividades de um domínio de negócio específico.

- Gateways ou passagens: É usado para controlar a divergência e a convergência da seqüência de um fluxo. Assim, determinará decisões tradicionais, como juntar ou dividir trajetos. Podem ser do tipo inclusiva, exclusiva ou paralela.

- Fluxo de sequência ou fluxo de dados: É usado para mostrar a ordem (seqüência) com que as atividades serão executadas em um processo.

- Swimlane: É utilizado quando o diagrama envolve duas entidades de negócio ou participantes que estão separados fisicamente no diagrama. Representa atores ou participantes envolvidos no processo. Define "quem faz o quê" colocando os eventos e os processos em áreas protegidas. Pode ser do tipo Pool ou Lane. 
- Swimlane-Pool: Um pool representa um participante no processo. Ele é utilizado para dividir um conjunto de atividades de outros pools, geralmente no contexto B2B, chamados de pools.

- Swimlane-Lane: Os objetos do tipo lanes são utilizados para separar as atividades associadas para uma função ou papel específico. Uma lane é a subdivisão dentro de um pool e é usada para organizar e categorizar as atividades.

- Artefato: Produto de uma tarefa ou atividade. Pode ser um documento impresso ou eletrônico, por exemplo. É qualquer elemento que represente o resultado da atividade.

- Fluxo de mensagem: É usado para mostrar o fluxo das mensagens entre dois participantes diferentes que os emitem e recebem.

- Associação: É usada para associar dados, texto, e outros artefatos com objetos de fluxo.

\subsubsection{Mapeamento de Processos}

A análise das organizações possibilita uma visão geral do fluxo e sequência das atividades, duração do ciclo, pessoas envolvidas, relações e dependências existentes no processo. Grande parte das organizações não dá a devida importância ao mapeamento de seus processos. A falta de padronização acarreta alguns transtornos que poderiam ser facilmente evitados se as organizações conhecessem seus processos, identificassem seus erros e trabalhassem na solução de seus problemas.

Segundo Santos (2007), o mapeamento de processos é a facilitação do entendimento do negócio, a possibilidade de comunicação e a identificação dos processos de melhoria. Por outro lado, as organizações que já deram o primeiro passo, e têm em seu poder o mapeamento de seus processos, precisam se utilizar das informações geradas.

O mapeamento de processos caminha junto com a modelagem de negócios, na busca pelo entendimento dos processos existentes. Essa busca visa implementar melhorias nesses processos ou propor a implantação de uma nova estrutura de gestão, voltada para os processos da organização.

Santos (2007) define também que o mapa de processos deve ser construído utilizando-se uma linguagem gráfica que possibilite: exibir os detalhes do processo de modo gradual e controlado, encorajar concisão e precisão na descrição do processo, focar a atenção nas interfaces do mapa do processo e prover uma análise de processos. A modelagem dos processos por sua vez, procura elaborar um mapa de processos e a documentação das suas propriedades e características, identificando as atividades realizadas e as informações e produtos que fluem entre elas. Em síntese, se pode afirmar que mapear processos complementa a proposta de se modelar os processos de negócio da organização, já que a modelagem detalha as informações apresentadas pelo mapa de processos.

O mapeamento dos processos nada mais é do que a análise de uma empresa. Antes de iniciar o mapeamento, é necessário entender o processo atual e 
identificar o ponto de partida que, nesse caso, consiste na definição dos aspectos que se deseja melhorar.

Este mapeamento traz vantagem competitiva, uma vez que o entendimento do fluxo e do encadeamento das atividades, pelos administradores e colaboradores, permite uma avaliação mais precisa dos processos. Além disso, a comunicação é facilitada pela exposição padronizada dos processos que estavam implícitos.

Antes de iniciar o mapeamento é necessário estabelecer: que informações deverão ser documentadas e qual o nível de detalhamento requerido; a facilidade de manutenção; e a notação utilizada. Esse conjunto de ações permite priorizar as informações necessárias e gerar diagramas claros e concisos de forma que todos na organização consigam compreender.

Normalmente nem tudo é executado conforme planejado, por isso é preciso corrigir e ampliar a visão, ouvir outros colaboradores, trabalhar baseado em fatos e observar o trabalho sob a ótica do processo.

O mapeamento de processos traz para a organização, alguns benefícios. Dentre eles, pode-se citar: redução de custos, redução do tempo de execução, melhoria da qualidade, aumento da produtividade, maior foco na satisfação dos clientes internos e externos, agilidade no gerenciamento de mudanças e maior compreensão da organização. Com isso, os problemas podem ser identificados, analisados e tratados com propostas de soluções e melhorias.

A falta do mapeamento, na maioria das vezes, esconde e camufla os erros da organização. Quando os problemas são identificados, a organização corre o risco de não apresentar o tratamento efetivo, por não conseguir identificar em que momento ou setores tais erros estão assentados.

É importante ressaltar que a proposta de mapeamento e modelagem de processos não é uma atividade voltada apenas para um perfil específico de organização. Esta deve ser implantada por todo tipo de organização, independente do ramo de atividade, tamanho e participação no mercado.

\section{O Processo Geral de Contração de Serviços de TI}

Esta Seção apresenta o mapeamento de processos de todas as fases de contratação de serviços de TI do MCTI (Ministério da Ciência, Tecnologia e Inovação). Esta modelagem foi feita baseada na experiência do autor como gestor de contratos de serviços de TI do órgão em questão, bem assim na Lei 8666/1993 (BRASIL, 1993), na IN 04/2008/2010 (BRASIL, 2008) e na orientação dos professores do curso de formação para assunção do cargo. 


\subsection{Unidade de Análise}

A unidade de análise é o Ministério da Ciência, Tecnologia e Inovação, órgão integrante do SISP - Sistema de Administração dos Recursos de Informação e Informática. Dessa forma, a contratação de serviços de TI de seguir as orientações contidas na IN 04/2008/2010 (BRASIL, 2008).

\subsection{Processo Geral}

A Figura 3.1 apresenta o diagrama do processo geral de contratação de serviços de TI no Ministério da Ciência, Tecnologia e Inovação. Como pode ser visto, este envolve outros processos que não são desenvolvidos no âmbito deste órgão, mas que estão intimamente relacionados.

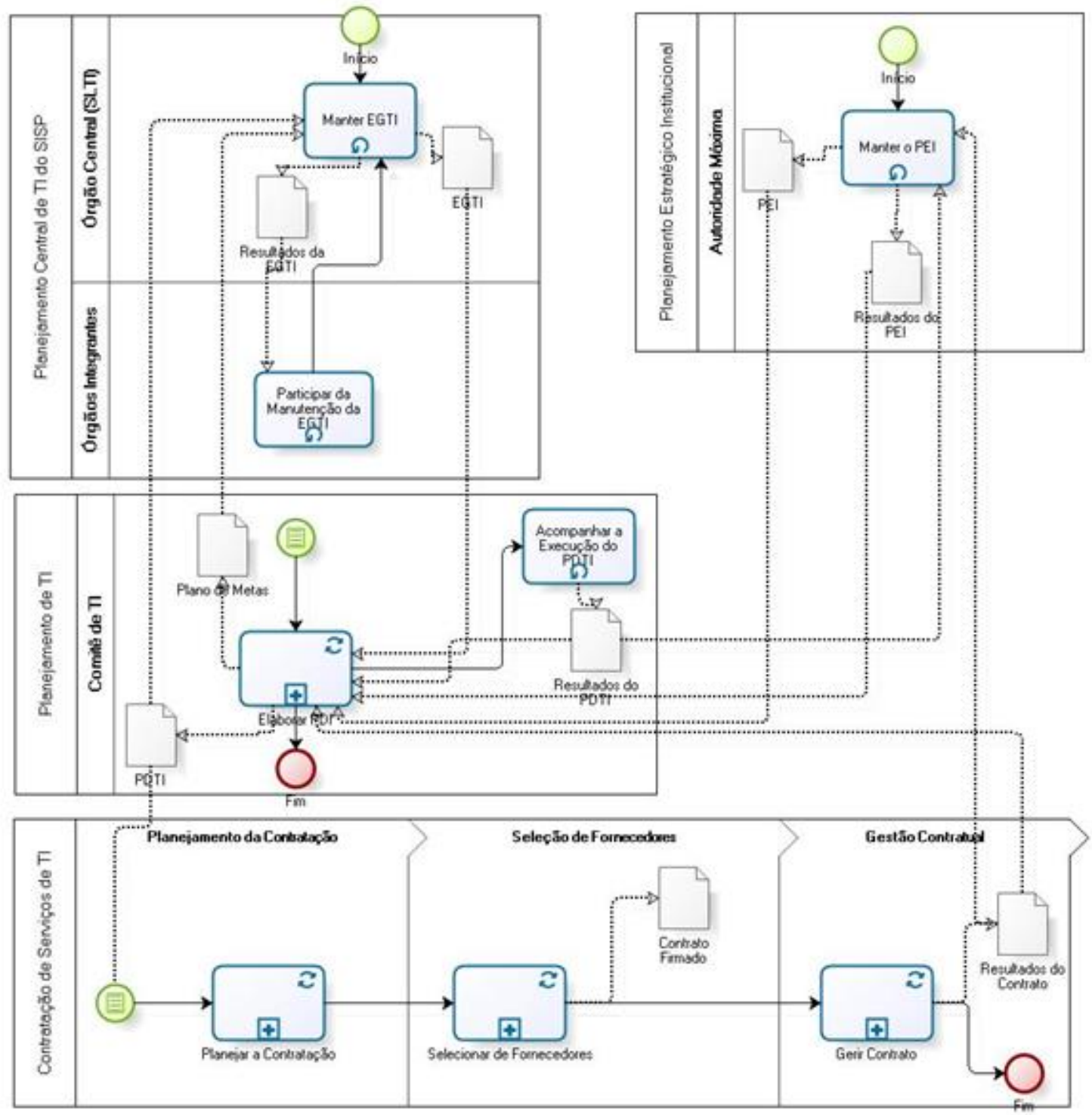

Figura 3.1: Processo Geral de Contratação de Serviços de TI.

Como pode ser observado na Figura 3.1, o comitê de TI é o responsável pelo andamento da contratação dos serviços de TI, pois é ele o incumbido pela 
elaboração e manutenção do PDTI (Plano Diretor de Tecnologia da Informação). Conforme determinação da IN 04, não se pode contratar serviços de TI sem que se tenha um PDTI vigente. Dessa forma, concentrar toda a responsabilidade de manutenção do instrumento no comitê gestor de TI, mesmo para fazer pequenas alterações, requer que este seja atuante, mas nem sempre é o que ocorre na maioria dos órgãos da APF. Sendo assim, é necessário que haja flexibilidade em relação a isso.

\subsection{Elaboração do PDTI}

A Figura 3.2 mostra o diagrama do processo de elaboração do PDTI. Como pode ser visto é um processo bastante complexo, pois é composto por várias tarefas e tem obedecer a uma série de requisitos, desde os legais até os relacionados ao planejamento estratégico institucional.

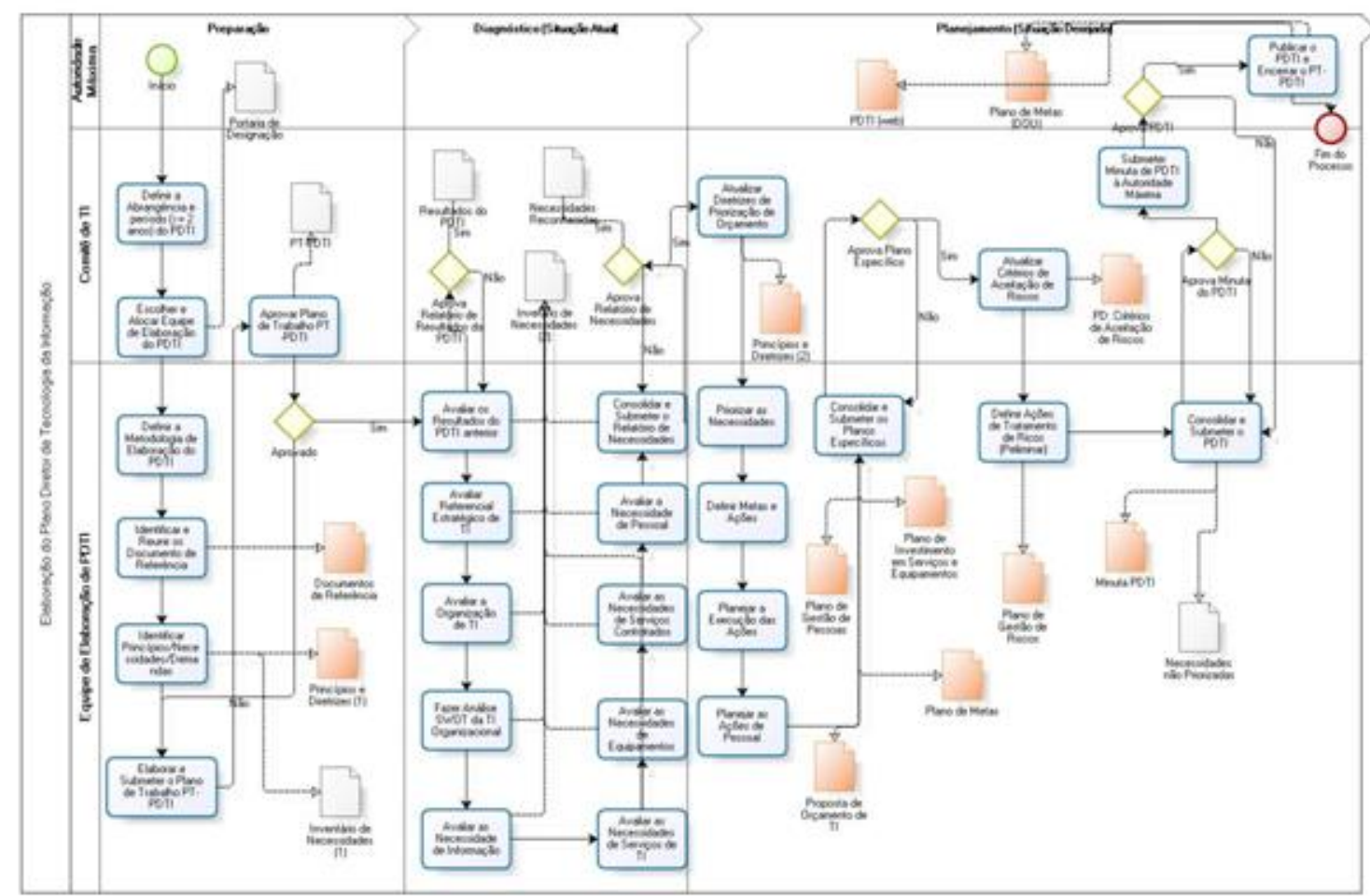

Figura 3.2: Processo de Elaboração do PDTI.

Este processo consiste em elaborar o PDTI para que seja possível iniciar o processo de contratação de serviços de TI, conforme diz o Art. $3^{\circ}$ da IN 04/2010 que diz o seguinte: "As contratações de que trata esta Instrução Normativa deverão ser precedidas de planejamento, elaborado em harmonia com o Plano Diretor de Tecnologia da Informação - PDTI, alinhado à estratégia do órgão ou entidade."

\subsection{Planejamento da Contratação}

A Figura 3.3, a seguir, mostra o diagrama do processo de planejamento da contratação. Esta fase contempla os serviços, produtos e outros elementos que compõem a Solução de Tecnologia da Informação que irá gerar o resultado 
esperado. Ela consiste nas seguintes etapas: Análise de Viabilidade da Contratação; Plano de Sustentação; Estratégia de Contratação; e Análise de Riscos.

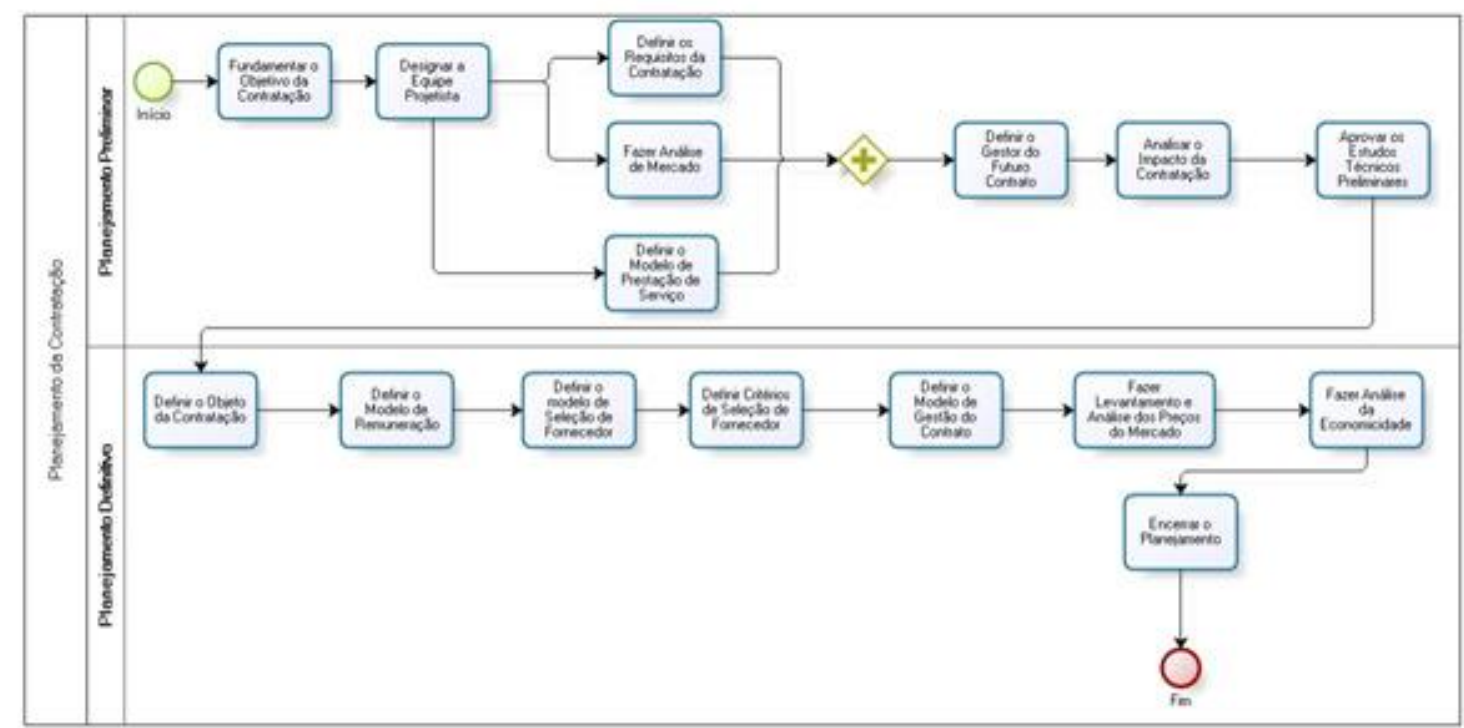

Figura 3.3: Processo de Planejamento da Contratação.

A fase de Planejamento da Contratação deve contemplar os serviços, produtos e outros elementos que compõem a Solução de Tecnologia da Informação que irá gerar o resultado esperado. Esta fase é composta de planejamento preliminar e definitivo, conforme pode ser observado na Figura 3.3.

\subsection{Seleção de Fornecedores}

A Figura 3.4, a seguir, apresenta o diagrama do processo de seleção de fornecedores. Este compreende a seleção e contratação de fornecedores. Ele vai desde a fase de edital até a assinatura do contrato. Na fase de seleção e contratação de fornecedor de um serviço demandado, a atuação da área de TI é bem restrita, cabendo à área administrativa a maioria das responsabilidades.

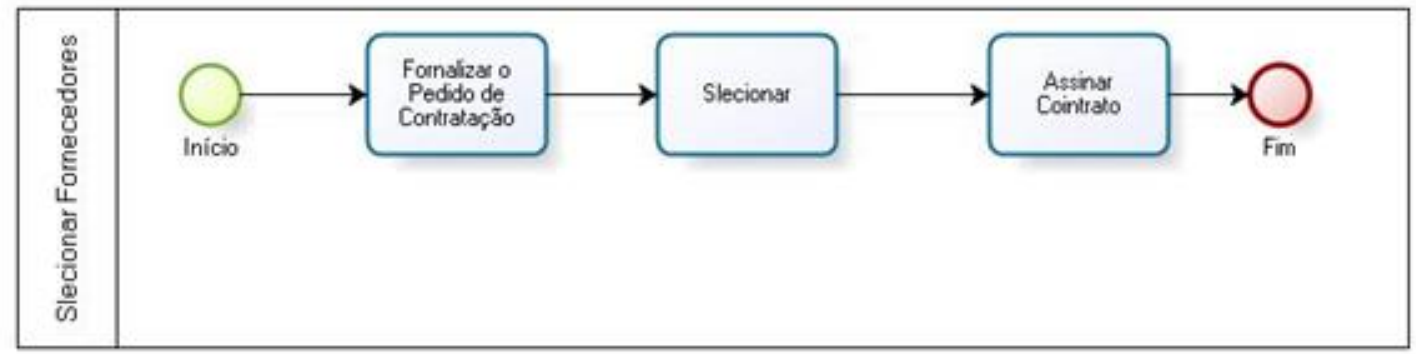

Figura 3.4: Processo de Seleção de fornecedores.

\subsection{Gestão Contratual}


A Figura 3.5, a seguir, mostra o diagrama do processo de gestão contratual. Este envolve as atividades superiores de planejamento, coordenação, supervisão e controle, relativas aos serviços, objeto de contratação, que visam a garantir o atendimento dos objetivos da organização.

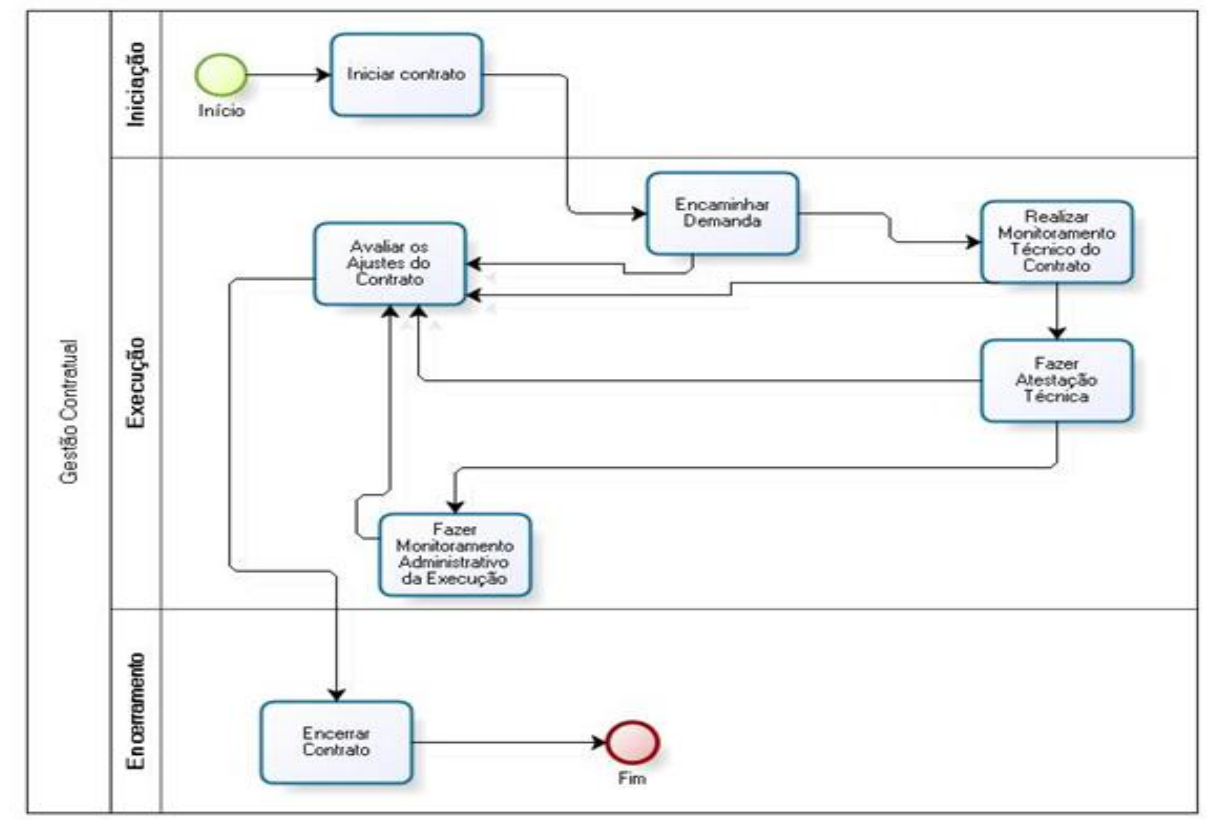

Figura 3.5: Processo de Gestão Contratual.

A fase de gestão contratual é aquela em que, tendo recebido delegação formal por meio do instrumento contratual, a área de TI assume a responsabilidade de gerenciar a execução do contrato de prestação de serviços de modo a garantir que os resultados e os benefícios pretendidos sejam alcançados, dentro dos custos previstos, ou seja, garantir a eficácia, eficiência, efetividade e economicidade do contrato.

\section{Análise do Modelo AS-IS}

Nesta Seção é apresentada uma análise dos resultados obtidos com o desenvolvimento deste trabalho. Esta é feita por processo, começando pelo geral até os subprocessos mapeados, e leva em consideração os seguintes fatores: importância do processo; como esse processo se relaciona com os demais e os benefícios que o mapeamento trouxe para a execução de cada um deles.

\subsection{Processo Geral de Contratação}

Este processo dá uma visão geral da contratação de serviços de TI na Administração Pública Federal, bem assim as responsabilidades de cada órgão na sua execução.

Este é o processo mais importante, pois é quem dita todas as regras e dá as diretrizes a serem seguidas para que se obtenha êxito na contratação. Ele é dividido em vários processos como a manutenção da EGTI, que tem como função 
dar as diretivas de todo o processo. Além disso, faz parte desta visão geral, a manutenção do Plano Estratégico Institucional, que é a principal entrada para a elaboração do PDTI.

Está relacionado com outros processos administrativos dos órgãos de controle, como edição instruções normativas e leis. Porém, estes não fazem parte do escopo deste trabalho, por isso não são apresentados aqui.

O mapeamento deste processo permitiu uma visão dos processos relacionados que norteiam o desenvolvimento dos termos de referência ou projetos básicos para contratação de serviços de TI. Isto facilita muito a atividade dos elaboradores destes artefatos, pois não é necessário mais buscar todas essas informações em vários documentos, basta usarem o diagrama, bem assim a sua descrição para se guiarem no momento da execução do seu trabalho.

\subsection{Processo de Elaboração do PDTI}

Este processo descreve as atividades desenvolvidas na elaboração do Plano Diretor de TI, são várias atividades a serem desenvolvidas e artefatos gerados. Este é uma exigência do TCU para a contratação qualquer contratação de serviços de TI.

A importância deste processo se dá pelo fato de, além de ser uma obrigação, relaciona todas as necessidades do órgão em termos de serviços de em um período mínimo de 2 anos. Vale dizer que se esse processo não for executado, não é possível dar sequência nos demais, que dependem dele. Ele está relacionado com todos os processos mostrados no diagrama do processo geral.

Os benefícios obtidos com o seu mapeamento é que as etapas de elaboração ficaram bem claras, de forma que se pode ter uma sequência das atividades a serem executadas em forma de fluxo de atividades, o que dá uma visão mais clara do que quando se usa textos.

\subsection{Processo de Planejamento da Contratação}

Com base no PDTI e na solicitação da área requisitante, inicia-se o processo de planejamento da contratação, que dita todas as regras para seleção dos fornecedores.

Este processo é importante porque é ele quem define o objeto da contração, a regras de remuneração e os critérios de habilitação. Está relacionado diretamente com o processo de requisição de serviços de TI, além do processo de elaboração do PDTI e do processo de seleção de fornecedores. O mapeamento deste processo trouxe vários benefícios, como a clareza no fluxo de trabalho a ser desenvolvido.

\subsection{Processo de Seleção de Fornecedores}

Este processo é executado durante a fase externa do processo geral, que é a seleção dos fornecedores, com no que foi especificado no processo anterior. Ele é realizado pelo setor administrativo do órgão e a participação da área de TI é mínima. 
A importância deste reside no fato de que é com a execução deste que se torna possível a geração do contrato e a obtenção do serviço propriamente dito. De maneira indireta, este processo se relaciona com todos os outros, mas com o planejamento da contratação ele está mais intimamente relacionado porque é este planejamento que dá a sustentação para a seleção dos fornecedores. Os benefícios trazidos pelo mapeamento deste processo não são tão significativos porque só dá uma visão de alto deste.

\subsection{Processo de Gestão Contratual}

O processo de gestão contratual é última fase da contratação de serviços de TI, é nesta que o serviço realmente é entregue para a área requisitante. Vale ressaltar que essa gestão inclui desde a fiscalização do serviço até a atestação deste para pagamento.

Este processo é muito importante, pois é ele quem atesta a qualidade dos serviços entregue, bem assim 0 andamento deste. Este se relaciona indiretamente com todos os demais, pois é a fase final do processo geral. Os benefícios obtidos com o mapeamento deste processo é que cada atividade é mostrada em sequência e os relacionamentos entre elas facilitam o trabalho do gestor.

\subsection{Processos Críticos}

Nesta seção são apresentados os processos mais críticos para a contratação de serviços e compra de produtos de Tecnologia da Informação. Tais processos foram selecionados de acordo com o tempo gasto para executá-lo, bem como devido à sua importância para que as contratações sejam executadas com sucesso.

\subsubsection{Avaliar as Necessidades de Serviços Contratados e de TI e de Equipamentos}

A execução destes processos (componentes do processo Elaborar PDTI) envolve a participação de todas as áreas dos órgãos para que sejam executados de forma adequada. Porém, isso leva muito tempo, mais do que o necessário, devido à falta de agenda, ou mesmo interesse por parte das áreas em indicar um representante para participara das reuniões de definições das necessidades.

O que torna estes processos críticos é o fato de serem essenciais para a elaboração do PDTI, dado que a recomendação do TCU é para contratar apenas o que foi definido nesse documento. Caso haja necessidade de se adquirir algum produto ou serviço de TI que não esteja nesse planejamento, é necessário que o comitê de TI se reúna para alterá-lo de forma que contemple essa nova demanda.

Outro grande problema enfrentado nessa fase é a falta de planejamento institucional, o que dificulta a definição do que se deve comprar nos próximos dois anos (tempo mínimo para validade do PDTI). 
A dificuldade na execução destes processos reside em dois fatores, não exclusivos, que são a falta de um planejamento institucional e dificilmente as áreas conseguem explicitar com clareza as suas necessidades.

\subsubsection{Avaliar a Necessidade de Pessoal}

A criticidade deste processo reside no fato de depender de fatores externos, mas especificamente do MPOG e da presidência da república, pois não basta apontar qual a necessidade de pessoal o órgão tem, mas também analisar se essa é possível de ser atendida, e se não for atendida quais procedimentos deverão ser tomados para que tudo saia de acordo com o planejado. A grande dificuldade na execução deste processo ocorre porque nem sempre é possível obter consenso entre as áreas envolvidas.

\subsubsection{Priorizar as Necessidades}

Um dos fatores que torna este processo crítico é por envolver uma ampla negociação com as áreas demandantes porque todas querem que as suas necessidades sejam atendidas primeiro. O que torna difícil a execução deste processo é que a TI não tem autonomia para decidir o que deve ser adquirido primeiro, mesmo que para atender a determinada demanda seja necessária a aquisição de equipamentos ou mudança na infraestrutura de TI.

\subsubsection{Fundamentar o Objetivo da Contratação}

Este processo, crítico por ser o ponto inicial da contratação, deve levar conta as diretrizes e políticas da Administração do órgão ou entidade em questão, consubstanciadas na forma de objetivos estratégicos, estratégias, metas e medidas constantes de seu planejamento de longo prazo e de seu planejamento de tecnologia da informação. Dessa forma, mais uma vez, surge a dificuldade de sua execução pelo fato de o órgão não ter um planejamento institucional.

\subsubsection{Definir os Requisitos da Contratação}

Este processo deve ser executado pela equipe de TI em conjunto com representante da área requisitante, o que torna uma tarefa bastante demorada, que atrapalha 0 andamento do trabalho. Demorada porque nem sempre 0 representante da área demandante sabe exatamente o que ela deseja. Isso sem falar que é muito difícil conseguir agendar reuniões para fazer tal definição.

\subsubsection{Fazer Levantamento e Análise dos Preços do Mercado}

Este processo envolve a análise de preços de mercado para sintetizar duas informações necessárias para a licitação, a estimativa do custo da contratação e o comportamento dos preços no mercado. A dificuldade em se realizar esta fase se encontra no fato de que nem sempre as fornecedoras de serviços ou produtos de TI atendem de maneira eficiente às pesquisas, o que leva a um grande atraso no processo.

\section{Discussão e Proposta de Melhoria (modelo TO-BE)}


Ao analisar o resultado obtido com este mapeamento, é possível perceber que alguns processos podem ser melhorados, como, por exemplo, maior participação da área de TI no processo de seleção de fornecedores.

Além do que foi dito acima, cabe ressaltar que só se pode executar um processo com perfeição quando este é conhecido de fato, e este trabalho trouxe esse conhecimento, inclusive dá base para propor melhorias.

Cabe ainda dizer que os resultados alcançados podem trazer os seguintes valores para o negócio: economia de recursos humanos e materiais - o tempo para elaboração dos termos de referência para contratação de serviços de TI é menor; melhoria na comunicação entre a área requisitante e a TI - os processos mapeados permitem um melhor entendimento entre a área de negócio e a TI; e diminuição da possibilidade de o edital ser interditado pelo TCU - tendo os processos mapeados, de acordo com as leis e normas pertinentes, a probabilidade de erros diminui.

\subsection{Proposta de Melhoria}

Esta proposta levou em consideração, também, o que reza a Nova Gestão Pública (NGP) que é orientada por resultados do processo decisório. Segundo Peregrino (2009), a NGP foi inspirado em reformas ocorridas em vários países nos anos 80, e preconiza a incorporação de instrumentos gerenciais do setor privado pelo setor público.

Para Martins (2005), a NGP destaca duas perspectivas, essencialmente, complementares, quais sejam: perspectiva finalística e perspectiva meio. A primeira

lida com a questão dos novos papéis do estado nas sociedades democráticas capitalistas progressivamente inseridas no contexto global, perspectiva esta que acena com um profundo processo de reordenamento institucional entre os domínios do estado, mercado e terceiro setor (MARTINS, 2005). Já a segunda lida com o modelo de gestão estatal em geral: a forma pela qual as finalidades são definidas; a estrutura macrogovernamental e a tipologia institucional; os processos de provimento de serviços; a gestão dos recursos organizacionais. A partir desta perspectiva, surge a necessidade de alinhar 0 modelo de gestão estatal às características dinâmicas dos novos contextos, o que impõe maior flexibilidade, ênfase nos resultados e foco no cliente (MARTINS, 2005).

Levando em conta que a área de TI está na perspectiva meio, ela deve estar alinhada ao modelo de gestão estatal e deve ter flexibilidade. Dessa forma, é necessário que ela participe da construção do planejamento estratégico do órgão, além de ter autonomia para tomar decisões que visem atender às expectativas da NGP.

Segue daí a necessidade de se criar uma subsecretaria para a essa área (TI), já que no modelo atual ela está ligada à subsecretaria administrativa, o que a torna dependente dessa, dificultando com isso a sua agilidade na tomada de decisão. 
A partir da criação de uma subsecretaria de TI, que poderia se chamar SPOTI (Subsecretaria de Planejamento e Orçamento de TI), propõe-se que o processo de contratação de serviços e aquisição de produtos de TI aconteça da seguinte forma: o Planejamento Estratégico Institucional (PEI) seria feito por representantes de todas as áreas, inclusive da de TI; a partir do PEI, a SPOTI elaboraria o Planejamento Estratégico de TI (PETI) e submeteria para aprovação ao comitê de TI; não haveria necessidade da participação das demais áreas na elaboração do PDTI (por se tratar de um planejamento tático), dado que o SPOTI teria autonomia para priorizar os investimentos, já que teria orçamento próprio, com base nas necessidades definidas no PEI e PETI; e o comitê de TI só se reuniria para tratar de assuntos estratégicos do órgão, pois as decisões operacionais seriam tomadas pela própria SPOTI, agilizando, com isso, o processo.

Assim, o processo geral de contração de serviços e aquisição de produtos de TI da APF fica conforme apresentado na Figura 5.1.

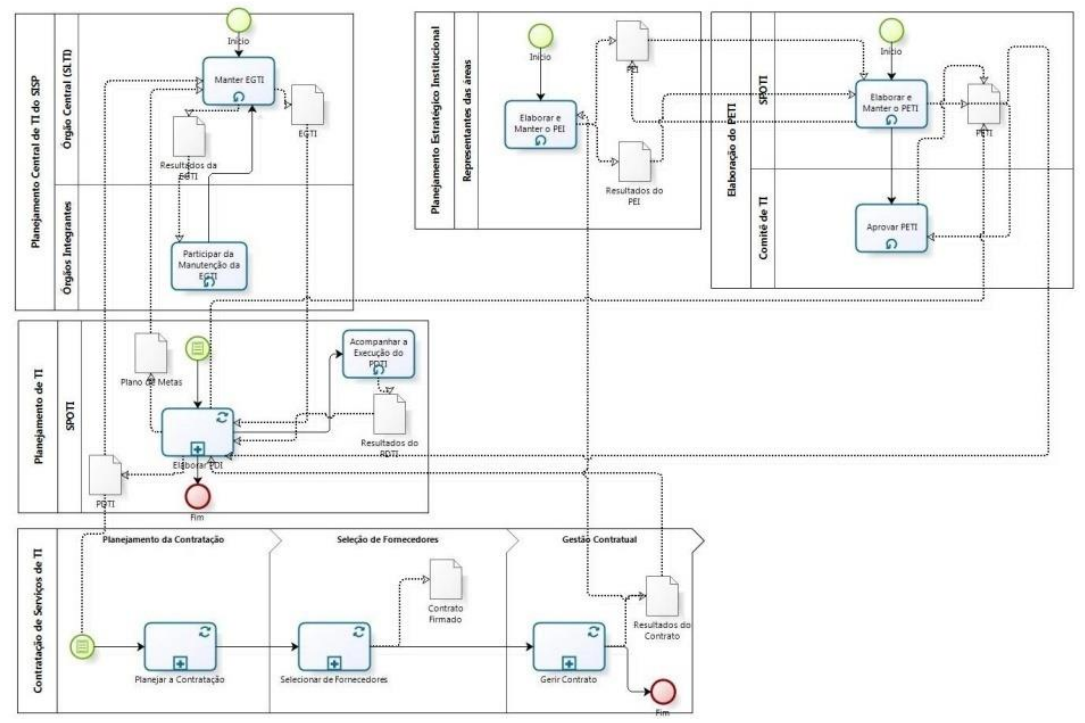

Figura 5.1: Proposta de melhoria no processo de contratação de TI

\section{Conclusões}

Este trabalho permitiu se ter uma visão clara de todo o processo de contratação de serviços de TI, além de facilitar o entendimento de alguns pontos que antes não estavam claros para a equipe responsável pela elaboração dos termos de referência.

Devido à dependência do PDTI para a contratação, percebeu-se que o processo crítico é a elaboração deste, não pela dificuldade de se executar a tarefa, mas sim por depender do Planejamento Estratégico Institucional, que nem sempre é feito e não depende da área de TI, que a responsável pela elaboração do Plano Diretor de TI.

Como esta é considerada apenas a fase inicial do projeto, sugere-se que se faça uma análise de ruptura para propor melhorias em alguns processos considerados 
críticos. Vale lembrar que essa análise ainda não foi feita porque não faz parte do escopo desta fase.

Tendo como principal objetivo entender o processo de contratação de serviços de TI, este trabalho mostrou que com o mapeamento de processos isso é totalmente possível. Além disso, isso facilita muito o trabalho da equipe responsável pela elaboração dos artefatos para contratação de serviços de TI.

Foi possível, ainda, constatar que o estudo do processo atual deu suporte à proposta de melhoria deste.

\section{Referências}

ARAUJO, Vanessa L. de. Regras de Negócio. Disponível em: < http://sysreq.iv.org.br/portal/down/apr/RegrasNegocio.pdf>. Acesso em: 27/09/2010.

BALDAM, Roquemar de $\mathrm{L}$ et al. Gerenciamento de Processos de Negócio: BPM - Business Process Management. 2. ed. São Paulo: Érica, 2007.

BITENCOURT, Mauricio. Modelagem de Processos com BPMN. Baguete, jul. 2007. Disponível em: <http://www.baguete.com.br/artigos/270/mauriciobitencourt/19/07/2007/modelagem-de-processos-com-bpmn>. Acesso em: 27/09/2010.

BRASIL. Decreto Lei $\mathbf{n}^{\circ} \mathbf{2 0 0}$, de 25 de fevereiro de 1967. Dispõe sobre a organização da Administração Federal, estabelece diretrizes para a Reforma Administrativa e dá outrasprovidências. Diário Oficial [da] República Federativa do Brasil. Brasília, DF, 17 jul. 1967. Disponível em:

<http://www.planalto.gov.br/ccivil/decreto-lei/Del0200.htm>. Acesso em: 21 ago. 2010.

Acórdão $\mathbf{n}^{0} \mathbf{7 8 6}$ - P, de 25 de maio de 2006. Dispõe sobre monitoramento de licitação para contratação de serviços de informática nas áreas de desenvolvimento de sistemas e acompanhamento de projetos. Brasília, DF, 26 mai. 2006. Disponível em:

<http://contas.tcu.gov.br/portaltextual/ServletTcuProxy>. Acesso em: 21 ago. 2010.

Acórdão n¹603 - P, de 13 de agosto de 2008. Dispõe sobre Levantamento para obter informações acerca da governança de TI na APF por meio da identificação de processos de aquisição de bens e serviços, de segurança da informação, de gestão de recursos humanos e das principais bases de dados e sistemas. Brasília, DF, 13 ago. 2008. Disponível em:

<http://www.jf.jus.br/cjf/tecnologia-da-informacao/gestaodocumental/tcu/acordao_tcu_-_13-08-2008.pdf/view>. Acesso em: 21 set. 2010.

Instrução Normativa $\mathbf{n}^{\circ} \mathbf{4}$, de 19 de maio de 2008. Dispõe sobre o processo de contratação de serviços de Tecnologia da Informação pela Administração Pública Federal direta, autárquica e fundacional. Brasília, DF, 20 mai. 2008. Disponível em: 
<http://www010.dataprev.gov.br/sislex/paginas/38/MPOG/2008/4.htm>. Acesso em: $21 / 08 / 2010$.

CRUZ, Cláudio S. da. Governança de TI e Conformidade Legal no Setor Público: um Quadro Referencial Normativo para a Contratação de Serviços de TI. Brasília, 2008. 254 f. Dissertação (Mestrado em Gestão de Conhecimento e Tecnologia da Informação) - Universidade Católica de Brasília, Brasília, 2008.

DÁVOLOS, Ricardo V. Modelagem de Processos. 4. ed. Palhoça-SC: UnisulVirtual, 2010.

FILHO, Airton Neubauer; ASSAD, Ricardo. BPM - business process management - monitorando a estratégia do negócio em tempos de governança corporativa. Gestão: Revista Científica de Administração e Sistemas de Informação,Curitiba, v. 8, n. 8, jan./jun. 2007.

LAURINDO, Fernando J. B. Gestão Integrada de Processos e da Tecnologia da Informação. São Paulo: Atlas, 2008.

MARTINS, Humberto F. Gestão de Recursos Públicos: orientação para resultados e acconutability. Revista Eletrônica Sobre a Reforma do Estado, Salvador, v. 1, n. 3, set./out./nov. 2005. Disponível em:

<http://www.direitodoestado.com/revista/RERE-3-SETEMBRO-2005-

HUMBERTO\%20MARTINS.pdf>. Acesso em: 07/07/2012.

MPOG. Padrão de Trabalho de Modelagem de Processos: Escritório de Processos. Dez. 2007. Disponível em:

<http://www.planejamento.gov.br/secretarias/upload/Arquivos/seges/081003_S EGES_Arq_padrao.pdf >. Acesso em: 25/09/2010.

SANTOS, Rildo F. Gestão por Processos: As Melhores Práticas para Gestão por Processos: 2007. Disponível em: <

http://www.companyweb.com.br/docs/Gestao_por_Processos-v3.pdf>. Acesso em: $27 / 09 / 2010$.

PEREGRINO, Fernando O. de F. A Nova Administração Pública no Brasil (1995/2009): Uma Avaliação do Modelo de Organização Socila na Área da Ciência e Tecnologia. Rio de Janeiro, 2009. 100 f. Dissertação (Mestrado em Ciências em Engenharia de Produção) - COPPE, Universidade Federal do Rio de Janeiro, RJ, 2009.

SORDI, José O. de et al. Competências críticas ao desenvolvimento de mapas cognitivos de redes interorganizacionais. Revista de Administração Pública, v. 43, n. 5, set./out. 2009. Disponível em:

$<$ http://www.scielo.br/scielo.php?script=sci_arttext\&pid=S0034-

76122009000500009 >. Acesso em: 25/09/2010.

VIEIRA, Marconi F. Gerenciamento de Projetos de Tecnologia da Informação. São Paulo: Campus, 2006.

Recebido em: $18 / 04 / 2013$

Aceito em: 28/06/2013 